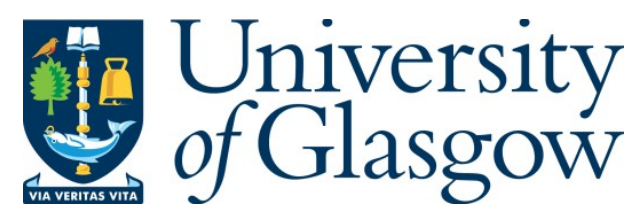

Wainman-Lefley, J., Goudie, N., Richardson, M. and Evans, J. (2020) A pilot feasibility study of a randomized controlled trial of goal setting using the Values in Action

Inventory of Strengths following brain injury. Neuropsychological Rehabilitation. (Early Online Publication)

(doi: $10.1080 / 09602011.2020 .1823428)$

This is the Author Accepted Manuscript.

There may be differences between this version and the published version. You are advised to consult the publisher's version if you wish to cite from it.

https://eprints.gla.ac.uk/223083/

Deposited on: 8 September 2020

Enlighten - Research publications by members of the University of Glasgow http://eprints.gla.ac.uk 


\title{
A pilot feasibility study of a randomized controlled trial of goal setting using the Values in Action Inventory of Strengths following brain injury
}

\author{
Jessica Wainman-Lefley ${ }^{1}$ Nicola Goudie ${ }^{2}$ Meghann \\ Richardson ${ }^{2}$ Jonathan Evans ${ }^{1^{*}}$
}

\footnotetext{
${ }^{1}$ Mental Health and Wellbeing, Institute of Health and Wellbeing, College of Medicine, Veterinary and Life Sciences, University of Glasgow

${ }^{2}$ Community Treatment Centre for Brain Injury, West Glasgow ACH, Dalnair Street, Glasgow

${ }^{*}$ Correspondence address:
}

Mental Health and Wellbeing

Administration building

Gartnavel Royal Hospital

1055 Great western Road

Glasgow

G12 OXH

E-mail: jessica.wainman-lefley@ggc.scot.nhs.uk

The authors report no conflict of interest.

Word count: 5,837 


\section{Abstract}

In a single-blind feasibility pilot randomised controlled trial design, brain injury (BI) participants were recruited from a community rehabilitation centre and randomised into goal-setting using the Values in Action Inventory of Strengths (VIA-IS), and goal-setting as usual. Outcomes included the feasibility and acceptability of the VIA-IS, and its use in setting goals in a $\mathrm{BI}$ rehabilitation context, and whether it affected types of goals set (International Classification of Functioning (ICF)). Memory for goals two weeks later was measured, and a sample size calculated for a full-scale trial. Twenty-six BI participants were recruited, and randomised to the VIA-IS $(n=13)$ and control group $(n=13)$. Two dropped out of the VIA-IS condition, leaving a total $n=24$. The majority (92\%) of participants rated the VIA-IS as acceptable; both groups described the goal-setting process as 'easy'. VIA-IS feedback varied; over two thirds (73\%) of VIA-IS participants used their VIA-IS results to set goals and described it as 'helpful'. There were no major differences in ICF categories between groups. A sample size of 66 would be required for a full-scale trial. A full-scale trial with multi-centre design appears warranted though might more clinically beneficial for difficult to engage BI clients.

Keywords: brain injury, goal-setting, goal planning, rehabilitation, positive psychology

Word count: 200 


\section{Introduction}

Brain injury $(\mathrm{Bl})$ can cause a plethora of physical, cognitive, and emotional sequelae, including impaired language, memory, motivation, concentration, self-identity, planning, and changes in mood and personality (Wilson, 2009; Ownsworth \& Haslam, 2016). One focus of neuropsychological rehabilitation is to support clients to learn strategies to overcome or manage these difficulties and to engage in personally meaningful activities.

Goal-setting is a core component of rehabilitation following BI (Playford et al., 2009). Evans (2012) argued that goal-setting is more than just an administrative task for rehabilitation teams, but is, or can be, a helpful intervention in the rehabilitation process. In particular, if clients are actively involved in the goal-setting process, they rate their experience of rehabilitation more positively, and the nature of the goals set as more personally relevant. Despite the development in the evidence base for goal setting methods, there remains large variations in how goals are set and used in a rehabilitation programme (Evans and Krasny-Pacini, 2017). Furthermore, goal directed behaviour and attainment can be affected by common cognitive deficits such those affecting selfawareness, motivation, and memory (Gauggel, Konrad, \& Wietasch, 1998). This has led to research investigating methods to improve memory for goals set for rehabilitation following $A B I$, with the aim of focussing attention and effort toward goal related activities (Hart et al., 2002; Culley \& Evans, 2010). Additional research has highlighted that memory prompting technologies are associated with significant improvements in remembering and carrying out daily activities, emphasising the link between memory and rehabilitation outcomes (Wilson et al., 2001; Pijnenborg et al., 2007).

Facilitators to goal-setting include clearer and more individually tailored goal-setting processes (Plant et al., 2016). Evidence has shown that personal relevance is important, having a motivating and empowering effect on engaging clients in rehabilitation; goals perceived as meaningful increase clients' perception of wellbeing, and improve goal achievement (Malec, 1999, Cheng, 2018, Holliday et al., 2007). Further, survivors of BI often have difficulty in formulating relevant goals for rehabilitation (Sherer et al., 1998), which may be due to impairments in cognitive functioning after BI. There is a need for research to identify effective ways to set goals in neurorehabilitation.

Positive psychology (PP) is the scientific study of positive individual traits, subjective experience, and institutions, and how these factors lead to improved quality of life (Seligman and Csikszentmihalyi, 2014). Evans (2011) emphasised the overlapping focus of 
PP with neuropsychological rehabilitation following traumatic BI, and the relevance and potential application of PP techniques within this setting. Since then, evidence has shown constructs of PP (resilience, character strengths, and positive mood states) are related to rehabilitation-related variables (perceptions of functional ability, and expectations of treatment); further highlighting the potential application of PP constructs to neurorehabilitation (Bertisch et al., 2014). Goals are a core part of positive psychology(Seligman, 2002), and evidence has demonstrated that growth occurs when individuals pursue goals that are consistent with their core values and beliefs (Sheldon \& HouserMarko, 2001). The amalgamation of goal-setting and positive psychology constructs may create a more personalised goal-setting process, which might benefit rehabilitation outcome following acquired $\mathrm{BI}$.

The Values in Action Inventory of Strengths (VIA-IS) is a central tool of PP, and is a reliable measure designed to identify individuals' profile of Character Strengths (Peterson and Seligman, 2004). Character Strengths are positive human traits considered to transcend cultures, and research has shown the identification and development of Character Strengths can lead to improvements in enjoyment and engagement of activities (Seligman et al., 2009). It is argued that there are 24 Character Strengths that fall within six value categories: Wisdom (curiosity, creativity), Courage (bravery, honesty), Humanity (love, kindness), Temperance (forgiveness, humility), Justice (leadership, teamwork), and Transcendence (gratitude, hope). The VIA-IS is not presently utilised during goal-setting in rehabilitation services after $\mathrm{BI}$, however other evidence from this field has indicated that when it is used within positive psychology interventions following brain injury, participants experience improved wellbeing (Cullen et al., 2018; Karagiorgou et al., 2018). We speculate that if goals are closely linked to personal values, they may be considered more personally meaningful and as a result, better remembered. This in turn may increase engagement with the rehabilitation process.

Given that the VIA-IS is not routinely used in community $\mathrm{BI}$ rehabilitation services to aid goal-setting, it is necessary to investigate whether it is feasible and acceptable to use the VIA-IS as part of the rehabilitation goal-setting process linking goals to personal values. To justify administering the VIA-IS, it would need to be demonstrated that it is beneficial over and above usual goal-setting procedures. 


\section{Current study}

The present study examined whether it is feasible to evaluate the use of the VIA-IS in the context of a randomised controlled trial (RCT) in which use of the VIA-IS in goal-setting is compared with usual goal-setting practice. We defined feasibility broadly in terms of whether it was possible to apply all of the procedures that would be required for a full randomised controlled trial (including recruiting, enrolling, and retaining participants, implementing the intervention, collecting outcome measures and blinding of researcher collecting outcome measures) and whether participants and clinical staff applying the study procedures reported that the study procedures (including use of the VIA-IS) were acceptable. We were interested whether using the VIA-IS aids the experience of goalsetting for BI participants and staff members who facilitate these sessions, and whether it affects the types of goals set and memory for goals two weeks later, above and beyond the current practice. We aimed to measure variance for the key outcome measure (memory for goals), so that we could calculate a sample size for future trial.

\section{Aims and hypotheses}

The primary aim of this study was to examine the feasibility and acceptability of using the VIA-IS in the goal-setting process for BI rehabilitation, within an RCT context.

The research questions related to:

Recruitment:

1. What number of potential participants identified fulfils eligibility criteria?

Enrolment:

2. What proportion of potential participants consent to participate?

Retention:

3. What number of participants can be followed-up at two weeks via telephone call?

Feasibility and acceptability of use of the VIA-IS: 
4. Is it feasible and acceptable to use the VIA-IS during the goal-setting process in a community treatment setting for brain injury?

i) What proportion of participants complete the VIA-IS?

ii) What feedback do BI participants provide regarding their experience of completing and using the VIA-IS to set goals?

iii) What feedback do $\mathrm{BI}$ rehabilitation clinicians provide regarding their experience of including the VIA-IS in the goal-setting process?

5. Is it feasible for the assessor to be blind to condition?

Additional research questions:

6. Does using the VIA-IS in the goal-setting process cause there to be differences in the categories of goals set compared with the typical method of goal-setting?

7. What is the measurement variance for the key outcome measure of memory for goals?

\section{Method}

\section{Design}

The study was a single-blind feasibility pilot RCT.

\section{Ethics}

Ethical approval was provided by West of Scotland Research Ethics Committee 4 (18/WS/0197). NHS Greater Glasgow and Clyde Research and Development granted board approval (GN18MH486).

\section{Participants}

Participants with a brain injury (BI) were recruited from the Community Treatment Centre for Brain Injury (CTCBI); a community-based service for adults aged 16 and over, who have experienced a $\mathrm{BI}$ (e.g. traumatic, subarachnoid haemorrhage, anoxic/hypoxic brain 
damage, encephalitis/meningitis). The $\mathrm{CTCBI}$ is an interdisciplinary team that provides client-centred interventions to reduce disability associated with $\mathrm{BI}$, and to assist clients to become independent. Clients are provided with a meeting for setting goals for rehabilitation, followed by a programme that focuses on engagement in meaningful and productive activities. The present study is a feasibility study of a new approach to goalsetting and therefore it is not powered to detect differences in outcome measures. The CTCBI typically assesses approximately twenty new BI clients a month. We estimated that approximately half of this population would be eligible and consent to take part, and so we expected to recruit roughly eight participants a month. We estimated from this that two groups of twenty-four participants would be recruited over six-months, which was the time initially available for data collection (subsequently extended to nearly seven months).

CTCBI clinicians who facilitated the goal-setting sessions provided feedback about the session, thus were also recruited as participants. The term 'CTCBI clinicians' refers to a core team of one Speech and Language Therapist, two Clinical Psychologists, and three Occupational Therapists who conduct the assessments and goal-setting at the CTCBI.

\section{Inclusion and Exclusion Criteria}

Inclusion criteria comprised clients with a previous $\mathrm{BI}$, referred to the $\mathrm{CTCBI}$, and were due to set goals as part of their engagement with the service. Exclusion criteria were clients under the age of 18 , those lacking the capacity to consent, and whose language ability (judged subjectively by CTCBI clinicians) would affect their ability to understand the VIA-IS questionnaire.

For CTCBI clinician participants, inclusion criterion was any CTCBI staff who assess new referrals to the service and facilitate goal-setting sessions as part of their job role.

\section{Recruitment Procedures}

\section{CTCBI clinician participants}

Potential CTCBI clinician participants were identified by a list of staff members, held by the site manager. The site manager checked inclusion criteria, and offered a participant information sheet to appropriate clinicians. CTCBI clinicians contacted the research team 
if they had any questions or wanted to participate, and they were then recruited via written consent.

\section{Brain injury participants}

Eligible $\mathrm{BI}$ clients were identified and invited to participate by CTCBI clinicians. Those interested were offered a participant information sheet at their first assessment, and permission was sought for the research team to contact them. After a week, potential participants received a phone call from the researcher, to answer any questions about the study and to seek verbal consent to take part. The researcher informed the CTCBI clinicians of agreeable potential participants, and they were consented into the study by a CTCBI clinician at their next appointment. A record was kept of the number of potential participants identified, approached, and consented.

\section{Measures}

Outcome measures for brain injury participants:

1) Data concerning participants' demographic characteristics were collected including age, gender, and postcodes to determine socioeconomic deprivation. Postcodes were transformed into Scottish Index for Multiple Deprivation (SIMD) 2016 quintiles, ranging from 1 (most deprived) to 5 (most affluent). Brain injury characteristics were collected from participants' self-reports, including; cause of injury and severity of injury (lowest Glasgow Coma Scale score, length of any loss of consciousness and of post-traumatic amnesia where known). Permission to access participants' medical records was sought during the consent process to check these details.

2) $\mathrm{BI}$ participants completed the VIA-IS 120 for adults. It is a validated measure designed to identify individuals' 24 Character Strengths profile (Peterson and Seligman, 2004). Participants completed the VIA-IS online using laptops. The number of participants who completed and reasons and number who did not complete the VIA-IS was recorded.

3) Participants' and CTCBI clinicians' feedback about the goal-setting session was obtained via a questionnaire at the end of the session. 
4) Memory for goals two weeks after they were set was measured as an indicator of how personal they were to participants (Culley and Evans, 2010). Participants received a phone call from the researcher two weeks after setting goals, who prompted them to recall their goals. The variance from these scores was used to calculate a sample size needed to power a full-scale trial of a similar nature.

5) For exploratory analysis, goals were categorised using the International Classification of Functioning, Disability, and Health (ICF) to see if the nature of the goal areas set was different between groups. ICF is the WHO framework for measuring health and health related domains (WHO, 2001). Goals were categorised using the ICF 2017 activities and participation categories (ICF codes d410-d6401) (Turner-Stokes, 2009, Choi et al., 2017). The categories include: 1) learning and applying knowledge, 2) general tasks and demands, 3) communication, 4) mobility, 5) self-care, 6) domestic (ife, 7) interpersonal interactions and relationships, 8) major life areas, and 9) community, and social and civic life. Following categorisation, any differences between groups were explored descriptively.

\section{Research Procedures}

At their second appointment at the CTCBI, willing $\mathrm{BI}$ participants were consented to the study and randomised into a goal-setting as usual group, or a goal-setting plus VIA-IS group, using a computer-generated block randomisation sequence created by a member of the research team not involved in assessment or treatment of participants. Only a CTCBI administrator who allocated participants to groups knew the sequence; the researcher was blind to it. Members of the clinical team delivering the goal setting could of course not be blind to allocation, but the researcher collecting outcome data was blind to group allocation. Participants were not informed which group was considered to be the 'active' intervention group.

\section{VIA-IS group goal-setting procedures}

Participants in the goal-setting plus VIA-IS group were asked to complete an online version of the VIA-IS on a laptop at the beginning of the goal-setting session. Participants were told to "not overthink answers to the questionnaire, to answer as honestly as possible" and were reminded that their answers were private. The CTCBI clinician who was present for the goal-setting session sat separately whilst participants completed the VIA-IS. Clinicians were instructed not to assist participants in answering the questions. When 
completed, participants' top five Character Strengths were generated, and flashcards with further information about them were provided.

The CTCBI clinician and participant set goals for rehabilitation using the guidance from the PoPsTaR manual (Cullen et al., 2018). Briefly, this involved giving examples of how Character Strength could be put into action, then participants were asked to think of examples where their Character Strengths might be seen in action in various areas of their life using a diagram of life areas. Participants then set goals and were invited to use the Character Strengths that they identified to help them, or they were free to select goals they had identified as important to them prior to recruitment. It was made clear that goals did not need to be linked to Character Strengths if this process was not helpful for producing meaningful goals. CTCBI staff were provided with training to discuss these procedures in order to manualise and standardise the process of goal-setting in the VIA-IS group.

\section{Control group goal-setting procedures}

Participants in the goal-setting as usual group set their goals for rehabilitation at the beginning of the session, using the typical method. CTCBI clinicians' reports show that this can vary; sometimes clients know their goals in advance, while others require some assistance from the clinicians to think of goals. Therefore, the 'goal-setting as usual' group was not standardised, however in doing this, it was representative of current practice. After the goal-setting as usual group set their goals for rehabilitation, they completed the VIA-IS. The purpose of this was to investigate whether clients' goals are consistent with their Character Strengths despite not knowing them.

\section{Procedures after goal-setting}

At the end of the goal-setting sessions, goals set were recorded on paper by the clinician, and CTCBI clinicians and all BI participants completed a feedback form evaluating their experience of goal-setting and of completing the VIA-IS for BI participants only. This data was passed to the researcher who uploaded in onto a database.

Replicating methods used in a study investigating memory of goals set for rehabilitation following BI (Hart et al., 2002, Culley and Evans, 2010), participants were telephoned two weeks after their goal-setting sessions and asked if they could recall their goals. Participants were informed that they would receive a telephone call, but not that this was 
the purpose of it, in order to avoid effects of effort to remember goals. Participants' exact verbal recall response from the telephone conversation was recorded on a database by the researcher, and compared with the goals set by the client at their session. Information was gathered about any further contact with participants between the goalsetting session and the follow-up telephone call, as this may affect memory for goals. After each call, the researcher guessed the allocation of each participant to determine the success of blinding.

Goals set were categorised into the ICF 2017 activities and participation categories (Oliveira et al., 2017, Rice et al., 2017). Information was also collected around participants not completing the VIA-IS or withdrawing from the study, to evaluate acceptability. Retention of participants to follow-up was noted to evaluate feasibility.

\section{Data Analysis}

Rates of recruitment, follow-up, declining to participate, and attrition during the study are reported using a CONSORT 2010 flow chart. The feedback from CTCBI clinicians and BI participants was summarised and differences in the average Likert scale responses compared visually. Types of goals set were described using the ICF classifications, they were then summed within categories and differences between groups were explored descriptively.

Participants' free recall of goals was scored with the criteria used by Culley and Evans (2010) and Hart et al (2002, p563), whereby participants were awarded points based on accuracy of recall. Three points were given if the response mirrored the original goal statement in terms of ideas and accuracy of content; two points if the participant recalled the general theme of the goal but was unable to provide further specific details, or their answer showed evidence of intrusions or distortions; and one point if the participant demonstrated a basic awareness of the goal but demonstrated significant distortions in content or was lacking in specific details. Zero points were given if participants provided a “don't know" response, had no recall, or their recall did not reflect goals in any way. Two independent researchers scored answers, and an interrater reliability analysis using the Kappa statistic was performed to determine consistency among raters. These scores were summed and averaged across all goals set. Variance in participants' free recall of goals in both conditions was calculated, to inform a sample size calculation for a future trial. 


\section{Results}

\section{Characteristics of the sample}

\section{CTCBI clinicians}

Six CTCBI clinicians were recruited: two Clinical Psychologists, one Speech and Language Therapist, and three Occupational Therapists.

\section{Brain injury participants}

Recruitment of BI participants occurred over an almost 7-month period (figure 1), between $4^{\text {th }}$ December 2018 and 30 th June 2019. A break in recruitment occurred for one week between $24^{\text {th }}$ December 2018 and $3^{\text {rd }}$ January 2019 due to staff holidays, and 2 weeks between $27^{\text {th }}$ February and $13^{\text {th }}$ March 2019 due to a temporary closure of the CTCBI, which was moving location.

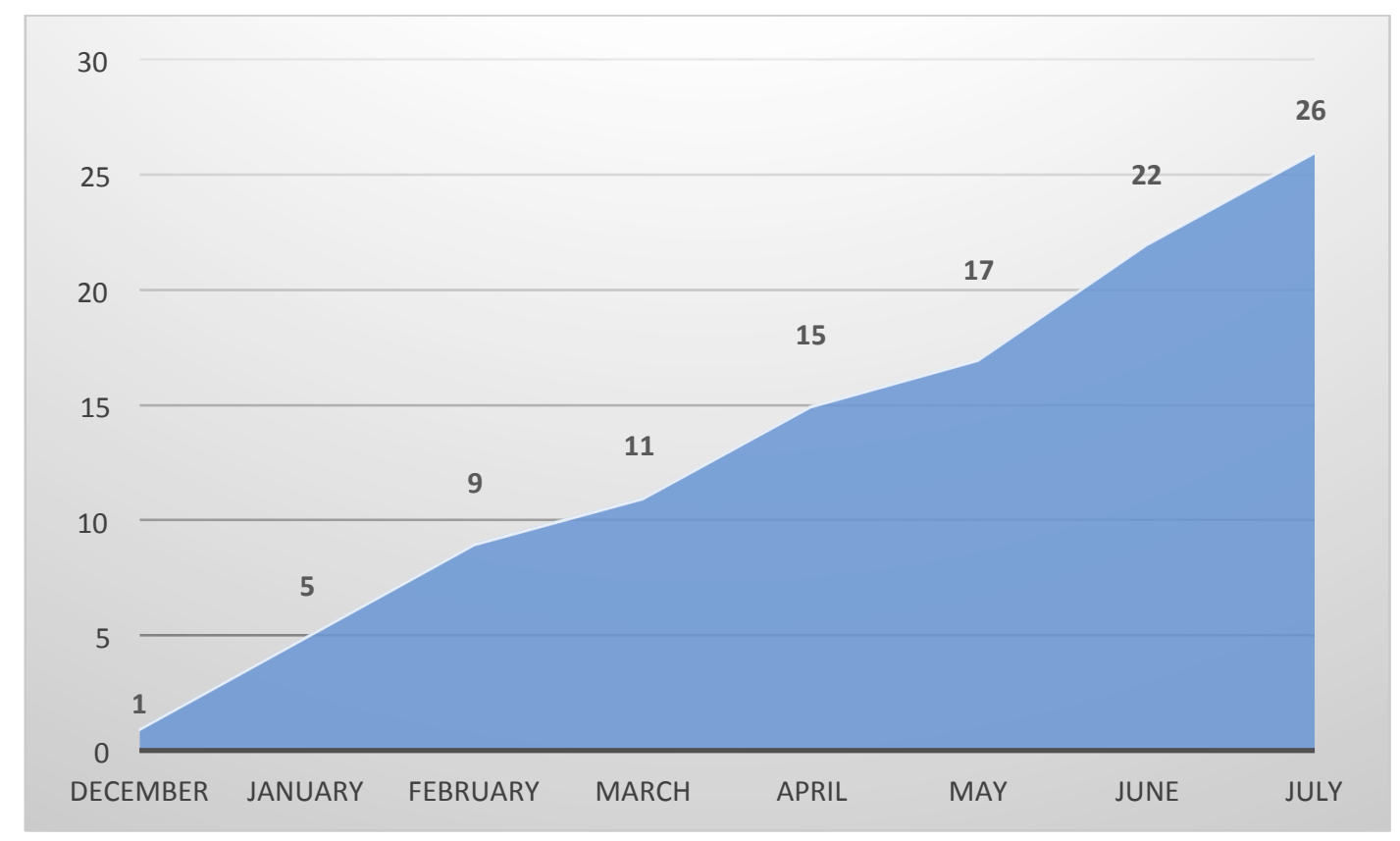

Figure 1: A stacked chart displaying recruitment figures of brain injury participants

Potential participants were identified from people referred to the CTCBI for initial assessment. A total of 115 potential patients were identified, of whom $n=50$ (43\%) were eligible, $n=18(16 \%)$ declined to participate, $n=6(5 \%)$ were identified but the study ended prior to recruitment, leaving $n=26(23 \%)$ who enrolled in the study. Figure 2 displays the CONSORT flow diagram of recruitment and follow-up of BI participants. This shows that $n=26$ were recruited. A total of $n=24$ (92\%) completed the study procedures. 
Two (8\%) participants did not complete the VIA-IS; for one person, the online questionnaire did not work correctly, and the participant became frustrated, and the other said it was boring, though the staff member sensed low motivation from the onset. Both ceased participation, and were in the VIA-IS group. All of the 24 participants who completed the study procedures were followed up for the two-week telephone call, 17 (71\%) were phoned exactly on the 2-week follow-up deadline, the remaining ranged from 1 - 12 days overdue (median $=2$, IQR: 1,7 ).

Figure 2: Consort 2010 flow diagram of brain injury participants' recruitment and dropout

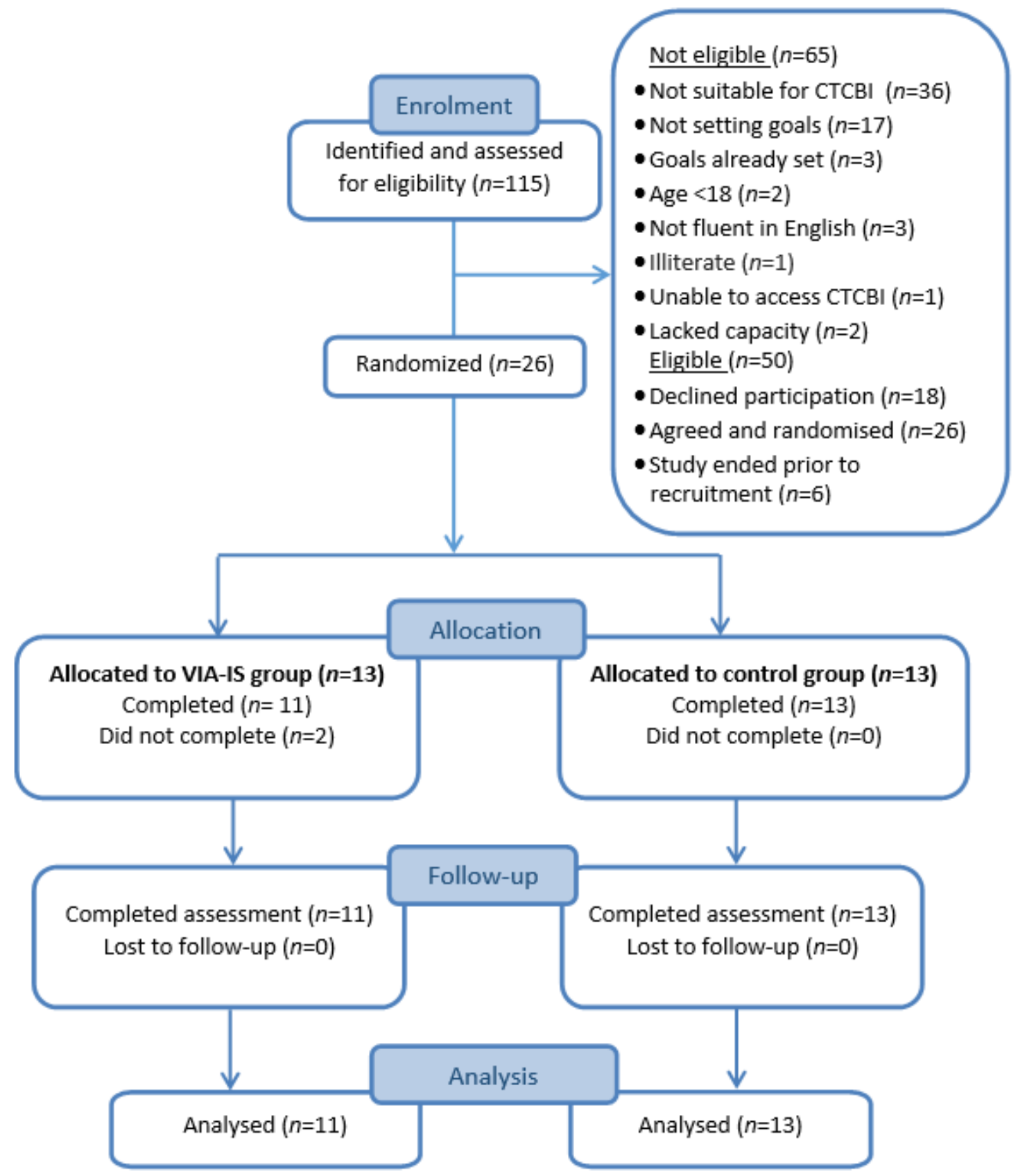


Demographic and clinical characteristics of the intervention and control group are shown in table 1. There was no difference between groups in age $(p=0.741)$ or SIMD quintiles ( $p$ $=0.241)$. There were more women in the intervention group, and more men in the control group ( $p<0.01, \phi=0.51$ ). The most common cause of injury in the intervention group was aneurysm, whereas the control group demonstrated more variation in cause of injury. The intervention group had more severe brain injuries in terms of longer length of posttraumatic amnesia and loss of consciousness, however the Glasgow Coma Scale score was similar in both groups indicating comparable severity of brain injuries by this classification.

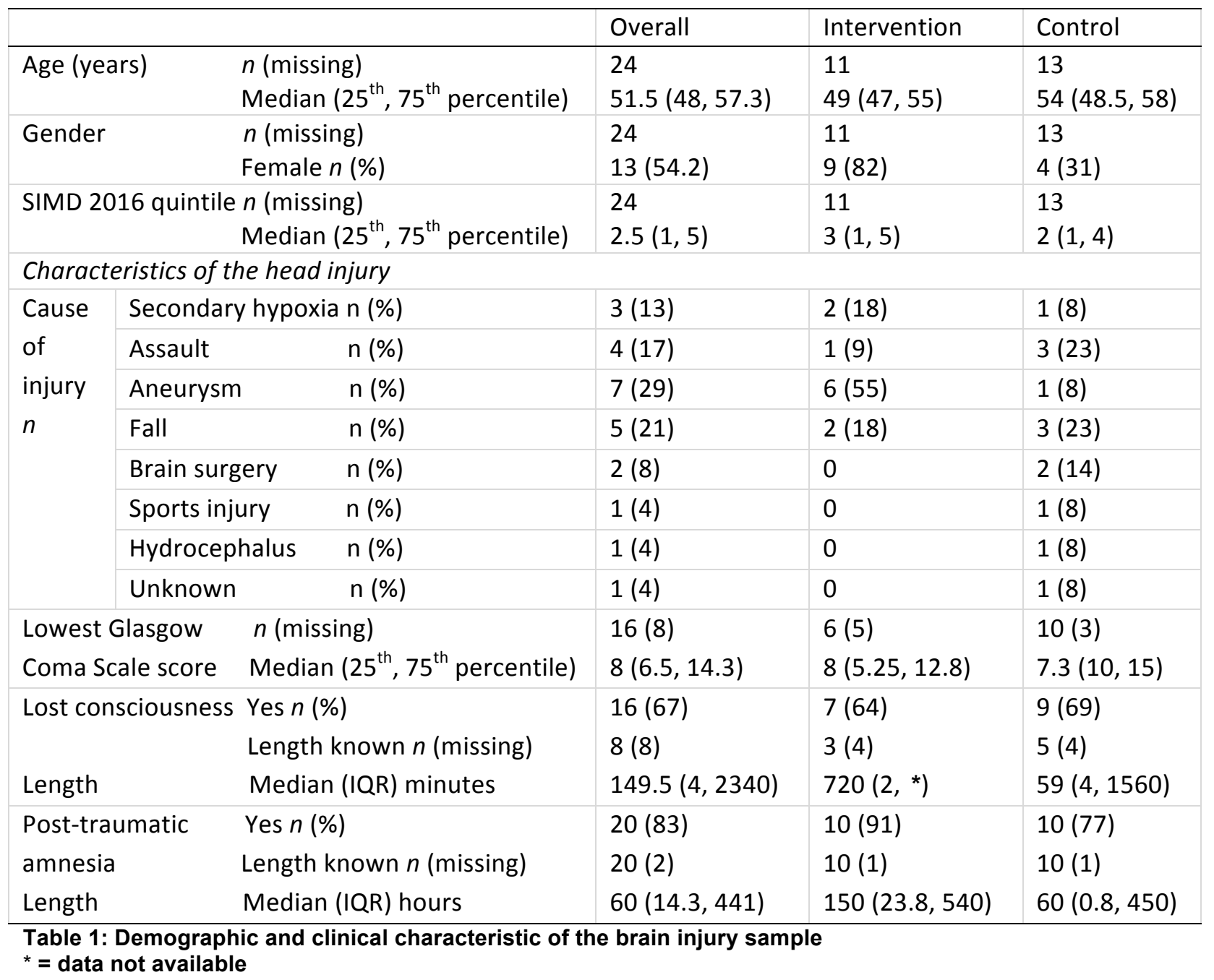

\section{Acceptability and feedback of the use of the VIA-IS in goal-setting}

The supplemental data includes the full feedback about completing the VIA-IS and setting goals from the $\mathrm{BI}$ participants in both groups and $\mathrm{CTCBI}$ clinicians, and the descriptions of the Likert scales. 
Of the twenty-four participants who completed the study procedures, twenty-two (92\%) participants said the VIA-IS was acceptable to complete. Within this group, participants gave mixed feedback. Some gave positive feedback, such as "I enjoyed the process and reflecting on my strengths", and it was "informative", "well designed", and "interesting", whilst others gave critical feedback, "It was repetitive", "It was confusing at points", and "the language was Americanised and some parts did not feel relevant to my culture". CTCBI clinicians also gave some positive feedback, "It was good for building rapport, and learning about the client. It created a level of engagement that I would not have gotten otherwise. It helped the client to articulate why the goal was important to them", and "It was a useful tool to get the client to think about different goals in relation to different areas of her life". Whereas for other participants, CTCBI clinicians commented, "The client found the wording confusing and the computer mouse difficult to operate" and "They required support using the computer. He struggled to read the screen and became frustrated with how long it took to complete".

There were two participants $(8 \%)$ who completed the VIA-IS and said it was not acceptable. One said, "It made me think about how different I am after my injury", and the other said, "Some items of the questionnaire were poor and harder to answer". A CTCBI clinician commented that one of these participants "required support using the computer, and found some of the language hard to understand. She was thinking about herself before the injury, and was worried about failing the questionnaire".

On average, participants in both groups rated their goals as "related" to their Character Strengths (VIA-IS: median = 4, IQR: 2, 5; control: median = 4, IQR: 3, 4.5). Similarly, participants' rating of how easy it was to set goals in the VIA-IS group (median $=4$ ("easy"), IQR: 3, 4) was the same as the control group (median = 4, IQR: 2.5, 4). CTCBI clinicians rated the goal-setting session as slightly easier in the control group (median $=5$, IQR: 4, 5) than the VIA-IS group (median = 4, IQR: 4, 4).

Of the eleven participants in the VIA-IS group who completed the study, $36 \%(n=4)$ used the VIA-IS results to set goals, 36\% $(n=4)$ used them a little, and $28 \%(n=3)$ did not. Of the $73 \%$ of these participants who did use the VIA-IS results to some extent, median rating score for how helpful it was to set goals was 4 ("helpful": IQR: 3.3, 4.8). CTCBI clinicians gave a median rating of 3 ("neither helpful nor unhelpful": IQR: 2, 3). 


\section{Categories of goals}

Table 2 displays the frequency of goals set organised by ICF 2017 activities and participation categories. Participants set the same number of goals, despite less participants in the control group. The control group showed a slightly higher frequency of goals in the following groups: learning and applying knowledge, general tasks and demands, community, and social and civic life, and domestic life. Participants in the VIAIS group set slightly more goals in the mobility, major life areas and interpersonal interactions and relationships categories. The largest differences were still minor.

\begin{tabular}{|l|l|l|}
\hline & $\begin{array}{l}\text { VIA-IS group }(\mathbf{n = 1 1}) \\
\text { frequency }\end{array}$ & $\begin{array}{l}\text { Control group }(\boldsymbol{n}=13) \\
\text { frequency }\end{array}$ \\
\hline 1 Learning and applying knowledge & 6 & 7 \\
\hline 2 General tasks and demands & 1 & 2 \\
\hline 3 Communication & 0 & 0 \\
\hline 4 Mobility & 1 & 0 \\
\hline 5 Self-care & 6 & 5 \\
\hline 6 Domestic life & 0 & 2 \\
\hline $\begin{array}{l}\text { 7 Interpersonal interactions and } \\
\text { relationships }\end{array}$ & 5 & 2 \\
\hline 8 Major life areas & 3 & 2 \\
\hline 9 Community, and social and civic life & 1 & 3 \\
\hline Total & 23 & 23 \\
\hline
\end{tabular}

Table 2: Brain injury participants' goals organised into ICF 2017 activities and participation categories

\section{Success of blinding}

All follow-up phone calls were conducted by a blinded assessor who guessed allocation at the end of the study. On 2 occasions (9\%) the assessor was unblinded; both participants were in the VIA-IS group. Of the remaining participants, $38 \%$ of group allocation was guessed correctly; $36 \%(n=4)$ of intervention participants and $46 \%(n=5)$ of control participants.

\section{Memory for goals}

Accuracy of memory for goals $(n=54)$ was rated by two independent researchers, with $87 \%$ agreement. The interrater reliability for the raters was found to be Kappa $=0.83(Z=$ $10.35, p<2.2 \mathrm{e}-16(p<0.0001), 95 \% \mathrm{Cl}(0.71,0.94))$, indicating almost perfect agreement (McHugh, 2012). 
Table 3 summarises participants' average memory for goals per participant. Participants' frequency of contact with the CTCBI service in-between goal-setting and follow up phone call was monitored to observe whether this might explain major differences in memory for goal. Both groups had little contact overall (VIA-IS: median =0, IQR: 0, 0; control: median $=0, I Q R: 0,1)$.

\begin{tabular}{|l|l|l|}
\hline & VIA-IS group $(\boldsymbol{n}=11)$ & Control group $(\boldsymbol{n}=13)$ \\
\hline Median (IQR) & $0.7(0.0,2.0)$ & $1.5(0.3,2.0)$ \\
Mean (SD) & $1.2(1.3)$ & $1.1(0.9)$ \\
\hline
\end{tabular}

Table 3: Average score for memory for goals at follow-up

\section{Sample size calculation for full-scale trial}

Memory for goals would be the primary outcome of interest in a future full-scale trial. The standard deviation of the mean memory score of all participants in this pilot trial was 1.03. It has been argued that using effect sizes derived from small pilot studies to estimate sample sizes required for a larger scale trial is inappropriate because the confidence intervals around those effect sizes is typically large (Westlund and Stuart, 2017). Instead, it is recommended that the minimum practically, or clinically, meaningful effect size is first determined. For some outcomes measures, consensus exits on minimal clinically important differences. However, for the primary outcome measure in this trial (memory for goals) there is no established consensus on a difference that would represent a minimal practically significant difference. We note that Culley and Evans (2010) found that their SMS reminding intervention produced a three point difference between conditions in memory for goals at 14 days post goal-setting, but again this was a very small sample so an estimate of effect size also cannot be determined with certainty. Our research team (with clinical experience of goal setting) considered this issue and concluded that a one point difference between groups would constitute a clinically important difference in recollection of goals, as this would represent a category change on the rating scale used (e.g. going from no recall of the goal to at least some recollection, or from having a general idea of the goal to a detailed recollection of the goal). A onepoint difference, with an SD of 1.03 reflects an effect size of 0.97 . With two-tailed alpha of 0.05 , power at 0.80 , a sample size of $n=18$ per group would be required to detect a significant difference between groups. However, to take a more cautious approach we would recruit 30 per group, which would provide power of 0.96 , to detect a betweengroups effect size of 0.97 . Assuming $92 \%$ retention, $n=33$ per group would be required to be randomised (total $n=66$ ). Based on numbers recruited compared to numbers eligible 
this would mean that 126 eligible participants would likely needed to be approached. Furthermore, given numbers eligible as a proportion of total referrals to the centre, this would mean that a total of 286 referrals to the centre would be required to be considered for eligibility.

\section{Discussion}

The primary aim of this study was to examine the feasibility and acceptability of using the VIA-IS in the goal-setting process for BI rehabilitation, within an RCT context. Recruitment to this pilot trial was challenging, however we recruited a small sample, which was representative of patients with $\mathrm{BI}$ attending community rehabilitation in Glasgow. We gained an understanding of realistic recruitment figures, as well as reasons for ineligibility of potential participants. Due to the slow recruitment rates at this one CTCBI site, it might be helpful to run a future RCT at multiple sites.

The dropout rate was low compared to the accepted rate of $20 \%$ for RCTs (Furlan et al., 2009 ), and the $100 \%$ follow-up of all participants who completed the study procedures is higher than an average of $6 \%$ loss to follow-up found across trials (Akl et al., 2012). There was slight variation in follow-up time; yet this is unsurprising in this clinical population where disability and disruption to lifestyle following injury is common (Thornhill et al., 2000). Sample attrition was different in the two arms, with the two withdrawals coming from the intervention arm. However, the stage at which they withdrew does not indicate it was related to the procedures of using the VIA-IS to set goals. BI participants said they withdrew because they found completing the VIA-IS challenging. Other feedback by BI participants about the acceptability of the VIA-IS was mixed, with some finding it interesting, informative, and enjoyable, whereas others criticised the length, and repetitive nature.

From the CTCBI clinicians' point of view, some noted that a few participants required support navigating the computerised questionnaire. Whereas for other BI participants, the clinicians commented that the VIA-IS was helpful for building rapport and engagement with clients and it assisted the process of thinking of a wider variety of goals. CTCBI clinicians rated goal-setting as slightly easier in the control group, however this might be related to familiarity with these procedures. BI participants in both groups rated the goalsetting procedures as 'easy'. Overall, it can be concluded that completing the VIA-IS appears mostly acceptable, however it may not be suitable for, or well received, by all patients, particularly if the person struggles with using computers or has difficulty 
concentrating. A limitation of the VIA-IS is that the language is Americanised and may not be understood as easily by other cultures, which was fed back by one participant in the study. It would be helpful to validate a British English version of this tool for use in the UK. The team behind the VIA-IS have recently created a shorter online version of the tool, which may improve its usability and acceptability.

This pilot study gained valuable feedback from the intervention group, using the VIA-IS to set goals. Of this group, $73 \%$ used the results of the VIA-IS in some form to set their goals, giving positive feedback such as finding it interesting and enjoying the process, and staff reported other benefits to the process of rehabilitation (rapport building). For those who did not use the VIA-IS, CTCBI clinicians commented that these participants knew what goals they wanted to set prior to the goal-setting session. There appears to be a place for VIA-IS in rapport building and engagement in rehabilitation, particularly for those who do not know what goals to set for rehabilitation, which should be investigated in future trials.

There were a few minor differences in ICF 2017 activities and participation categories of the goals, therefore using the VIA-IS to set goals did not appear to significantly alter the types of goals set. With the exception of two cases where the researcher was unblinded to group allocation, group allocation guessing was kept to almost chance level, indicating it is feasible to blind the researcher to the conditions in an RCT of this nature. The number of participants recruited was smaller than originally planned but were sufficient to be able to estimate the key statistical parameters needed to plan an RCT. An adequately powered RCT to detect a clinically meaningful difference score in memory for goals following a goal-setting intervention will need to be 66 , which is practical.

In terms of memory for goals two weeks after they were set, there was considerable variability in scores in both groups, with median/mean scores being close to 1 , which reflected in general participants had 'a basic awareness of the goal but demonstrated significant distortions in content or was lacking in specific details'. This highlights once again that despite the importance of goal setting in rehabilitation it remains challenging for many participants to recall the details of their goals. Given that examining efficacy was not a focus of this feasibility study it is important not to draw conclusions in relation to any differences between the groups. However, the question arises as to whether any adaptations to the VIA-IS intervention might enhance further participant's ability to remember their goals. One possibility is that a more extensive review/recap of the link between the goals set and their character strengths may help reinforce the 
meaningfulness of the goal to the individual and in doing so enhance memory for the goal. In practice, use of additional reminders regarding goals, such as the SMS message reminders evaluated by Culley and Evans (2010) may be important if goals are to be remembered, though it would be premature to add these reminders as part of a research evaluation of the VIA-IS given it would be difficult to separate out the effect of the reminders from use of the VIA-IS. It is noteworthy that at the two-week outcome point in the Culley and Evans (2010) study the median score in terms of memory for goals for which SMS reminders were sent was 1.67 per goal, and it was 0.67 for goals for which no reminder was sent. In the present study both groups fell between these values. Again, given the small samples in both this study and in Culley and Evans (2010) it is not appropriate to compare scores statistically but it seems clear that memory for goals could be improved further.

\section{Strengths and limitations}

Should a future study consider a similar design and conduct of an RCT for VIA-IS in community rehabilitation following $\mathrm{BI}$, the addition of a fidelity checklist would help to standardise the process of goal-setting in the VIA group, to ensure consistency across practice. Future studies may benefit from assessing cognitive impairments to control for how they might impact participants' recall of goals. A limitation of the study is that we did not set apriori criteria for progression to a full trial. Although we consider that data relating to key elements necessary for a full trial make it feasible (e.g. rate of recruitement, retention, acceptability of the intervention), it would have been helpful to set aprori progression criteria in relation to these variables. A strength of this study was the blinding of participants to the between group nature of the study, and therefore their own group allocation. This encourages unbiased feedback by the $\mathrm{BI}$ participants. Conversely, a further limitation was the lack of blinding of CTCBI staff, therefore their knowledge of study group and hypothesis of the study may bias their subjective feedback. A future trial would benefit from blinding therapist to prevent any bias in feedback. Nevertheless, research has established that this is challenging in a rehabilitation setting (Wade et al., 2010).

\section{Conclusion}

Although the sample size was small, it was adequate for obtaining information about the recruitment strategy, and helpful feedback from those who did and did not complete the 
study, which will contribute to future designs of RCTs in this field. A full-scale RCT using the VIA-IS to set goals for community rehabilitation following $\mathrm{BI}$ appears to be feasible, however clinical benefit may be limited to specific $\mathrm{BI}$ clients who are computer literate, more difficult to engage, and do not know what goals they want to set for rehabilitation. A multi-centre design to achieve sufficient sample sizes to detect the effects of the intervention will aid the recruitment of this specific, yet sometimes challenging to engage client group. 


\section{References}

Akl, E. A., Briel, M., You, J. J., Sun, X., Johnston, B. C., Busse, J. W., Mulla, S., Lamontagne, F., Bassler, D. \& Vera, C. 2012. Potential impact on estimated treatment effects of information lost to follow-up in randomised controlled trials (LOST-IT): systematic review. Bmj, 344, e2809.

Bertisch, H., Rath, J., Long, C., Ashman, T. \& Rashid, T. 2014. Positive psychology in rehabilitation medicine: A brief report. NeuroRehabilitation, 34, 573-585.

Cheng, W. L. 2018. The effects of mutual goal-setting practice in older adults with chronic illness. Geriatric Nursing, 39, 143-150.

Choi, K., Peters, J., Tri, A., Chapman, E., Sasaki, A., Ismail, F., Boulias, C., Reid, S. \& Phadke, C. P. 2017. Goals set by patients using the ICF model before receiving botulinum injections and their relation to spasticity distribution. Physiotherapy Canada, 69, 113-119.

Cullen, B., Pownall, J., Cummings, J., Baylan, S., Broomfield, N., Haig, C., Kersel, D., Murray, H. \& Evans, J. J. 2018. Positive PsychoTherapy in ABI Rehab (PoPsTAR): a pilot randomised controlled trial. Neuropsychological rehabilitation, 28, 17-33.

Culley, C. \& Evans, J. J. 2010. SMS text messaging as a means of increasing recall of therapy goals in brain injury rehabilitation: a single-blind within-subjects trial. Neuropsychological Rehabilitation, 20, 103-119.

Evans, J. J. 2011. Positive psychology and brain injury rehabilitation. Brain Impairment, $12,117-127$.

Evans, J. J. 2012. Goal setting during rehabilitation early and late after acquired brain injury. Current opinion in neurology, 25, 651-655.

Evans, J. J., \& Krasny-Pacini, A. (2017). Goal setting in rehabilitation. In B. A. Wilson, J. Winegardner, C. M. van Heugten, \& T. Ownsworth (Eds.), Neuropsychological rehabilitation: The international handbook (p. 49-57). Routledge/Taylor \& Francis Group

Furlan, A. D., Pennick, V., Bombardier, C. \& Van Tulder, M. 2009. 2009 updated method guidelines for systematic reviews in the Cochrane Back Review Group. Spine, 34, 1929-1941.

Gauggel, S., Konrad, K. and Wietasch, A. 1998. Neuropsychological Rehabilitation, Weinheim: Psychologie Verlags Union.

Hart, T., Hawkey, K. \& Whyte, J. 2002. Use of a portable voice organizer to remember therapy goals in traumatic brain injury rehabilitation: a within-subjects trial. The Journal of head trauma rehabilitation, 17, 556-570.

Holliday, R. C., Cano, S., Freeman, J. A. \& Playford, E. D. 2007. Should patients participate in clinical decision making? An optimised balance block design controlled study of goal setting in a rehabilitation unit. Journal of Neurology, Neurosurgery \& Psychiatry, 78, 576-580.

Karagiorgou, O., Evans, J. J., \& Cullen, B. (2018). Post-traumatic growth in adult survivors of brain injury: A qualitative study of participants completing a pilot trial of brief positive psychotherapy. Disability and rehabilitation, 40(6), 655-659.

Malec, J. F. 1999. Goal attainment scaling in rehabilitation. Neuropsychological Rehabilitation, 9, 253-275.

Mchugh, M. L. 2012. Interrater reliability: the kappa statistic. Biochemia medica: Biochemia medica, 22, 276-282.

Oliveira, J. S., Hassett, L., Sherrington, C., Ramsay, E., Kirkham, C., Manning, S. \& Tiedemann, A. 2017. Factors associated with the setting of function-related goals among community-dwelling older people. Journal of aging and physical activity, 122. 
Ownsworth, T., \& Haslam, C. (2016). Impact of rehabilitation on self-concept following traumatic brain injury: An exploratory systematic review of intervention methodology and efficacy. Neuropsychological Rehabilitation, 26(1), 1-35

Peterson, C. \& Seligman, M. E. 2004. Character strengths and virtues: A handbook and classification, Oxford University Press.

Pijnenborg, G. H. M., van den Bosch, R. J., Evans, J. J., \& Brouwer, W. H. 2007. SMS text messages as a prosthetic aid in the cognitive rehabilitation of schizophrenia. Rehabilitation Psychology, 52, (2), 236-240.

Plant, S. E., Tyson, S. F., Kirk, S., \& Parsons, J. (2016). What are the barriers and facilitators to goal-setting during rehabilitation for stroke and other acquired brain injuries? A systematic review and meta-synthesis. Clinical rehabilitation, 30(9), 921-930.

Playford, E. D., Siegert, R., Levack, W. \& Freeman, J. 2009. Areas of consensus and controversy about goal setting in rehabilitation: a conference report. Clinical rehabilitation, 23, 334-344.

Rice, D. B., Mcintyre, A., Mirkowski, M., Janzen, S., Viana, R., Britt, E. \& Teasell, R. 2017. Patient-Centered Goal Setting in a Hospital-Based Outpatient Stroke Rehabilitation Center. PM\&R.

Seligman, M. E. \& Csikszentmihalyi, M. 2014. Positive psychology: An introduction. Flow and the foundations of positive psychology. Springer.

Seligman, M. E., Ernst, R. M., Gillham, J., Reivich, K. \& Linkins, M. 2009. Positive education: Positive psychology and classroom interventions. Oxford review of education, 35, 293-311.

Seligman, M.E.P. 2002. Positive psychology, positive prevention, and ositive therapy. In C.R. Snyder (Ed.), Handbook of positive psychology. New York: Oxford University, pp.3-9.

Sheldon, K.M, Houser-Marko, L. 2001. Self-concordence, goal attainment, and the pursuit of happiness: Can there be an upward spiral? Journal of Personaility and Social Psychology, 80 (1) 152.

Sherer, M., Oden, K., Bergloff, P., Levin, E. \& High Jr, W. M. 1998. Assessment and treatment of impaired awareness after brain injury: Implications for community reintegration. NeuroRehabilitation, 10, 25-37.

Thornhill, S., Teasdale, G. M., Murray, G. D., Mcewen, J., Roy, C. W. \& Penny, K. I. 2000. Disability in young people and adults one year after head injury: prospective cohort study. Bmj, 320, 1631-1635.

Turner-Stokes, L. 2009. Goal attainment scaling (GAS) in rehabilitation: A practical guide. Clinical Rehabilitation, 23, 362-370.

Wade, D. T., Smeets, R. J. \& Verbunt, J. A. 2010. Research in rehabilitation medicine: methodological challenges. Journal of clinical epidemiology, 63, 699-704.

Westlund, E., \& Stuart, E. A. 2017. The Nonuse, Misuse, and Proper Use of Pilot Studies in Experimental Evaluation Research. American Journal of Evaluation, 38(2), 246-261.

Who 2001. ICF: International Classification of Functioning. Disability and Health. World Health Organisation, Geneva.

Wilson, B. A., Gracey, F. \& Evans, J. J. 2009. Neuropsychological rehabilitation: Theory, models, therapy and outcome, Cambridge University Press.

Wilson, B. A., Emslie, H., Quirk, K., \& Evans, J. J. 2001. Is Neuropage effective in reducing everyday memory and planning problems? A randomised control crossover study. Journal of Neurology, Neurosurgery and Psychiatry, 70, 477-482. 
Supplemental data 1: Brain injury participants' responses about completing and using the VIA-IS

\begin{tabular}{|c|c|c|c|}
\hline & Overall & Intervention group & Control group \\
\hline $\begin{array}{l}\text { Acceptable } n(\%) \\
\text { Comments: }\end{array}$ & $22(92)$ & $\begin{array}{l}10 \text { (90) } \\
\text { It was straight forward } \\
\text { It was easy to understand } \\
\text { It was confusing at points } \\
\text { I enjoyed the process and } \\
\text { reflecting on my strengths } \\
\text { The language of the VIA-IS } \\
\text { was Americanised and did } \\
\text { not feel relevant to my } \\
\text { culture } \\
\text { Easy to understand and } \\
\text { informative }\end{array}$ & $\begin{array}{l}12(92) \\
\text { I was happy to help } \\
\text { It was repetitive }(n=2) \\
\text { It was confusing at points } \\
\text { It was interesting } \\
\text { There were too many questions } \\
\text { about groups } \\
\text { I enjoyed it: it made me look at } \\
\text { myself and see some positives, } \\
\text { and it showed me where I need } \\
\text { to do some work. It also } \\
\text { showed me how surgery has } \\
\text { changed me for the better } \\
\text { Questionnaire was quick to } \\
\text { complete and well designed. I } \\
\text { agreed with the outputs. }\end{array}$ \\
\hline $\begin{array}{l}\text { Not acceptable } n(\%) \\
\text { Comments: }\end{array}$ & $2(11)$ & $\begin{array}{l}1 \text { (10) } \\
\text { It made me think about } \\
\text { how different I am after } \\
\text { my injury }\end{array}$ & $\begin{array}{l}1(8) \\
\text { Some items of the } \\
\text { questionnaire were poor and } \\
\text { harder to answer }\end{array}$ \\
\hline $\begin{array}{l}\text { Do you think your } \\
\text { goals are related to } \\
\text { one of your } \\
\text { Character Strengths? } \\
\text { Really not related (1) } \\
\text { Slightly unrelated (2) } \\
\text { Neither (3) } \\
\text { Related (4) } \\
\text { Really related (5) } \\
\text { Median Likert rating } \\
\text { (IQR) }\end{array}$ & $\begin{array}{l}n=24 \\
(100 \%)\end{array}$ & $\begin{array}{l}n=2(19 \%) \\
n=1(9 \%) \\
n=0 \\
n=4(36 \%) \\
n=4(36 \%) \\
4(2,5)\end{array}$ & $\begin{array}{l}n=2(16 \%) \\
n=0 \\
n=4(30 \%) \\
n=4(30 \%) \\
n=3(24 \%) \\
4(3,4.5)\end{array}$ \\
\hline $\begin{array}{l}\text { How easy was it to } \\
\text { identify your goals? } \\
\text { Very hard (1) } \\
\text { Slightly hard (2) } \\
\text { Neither (3) } \\
\text { Easy (4) } \\
\text { Very easy (5) }\end{array}$ & $\begin{array}{l}n=24 \\
(100 \%)\end{array}$ & $\begin{array}{l}n=11(100 \%) \\
n=0 \\
n=2(18 \%) \\
n=2(18 \%) \\
n=5(46 \%) \\
n=2(18 \%)\end{array}$ & $\begin{array}{l}n=13(100 \%) \\
n=1(8 \%) \\
n=2(16 \%) \\
n=1(8 \%) \\
n=7(52 \%) \\
n=2(16 \%)\end{array}$ \\
\hline $\begin{array}{l}\text { Median Likert rating } \\
(\mathrm{IQR})\end{array}$ & & $4(3,4)$ & $4(2.5,4)$ \\
\hline
\end{tabular}




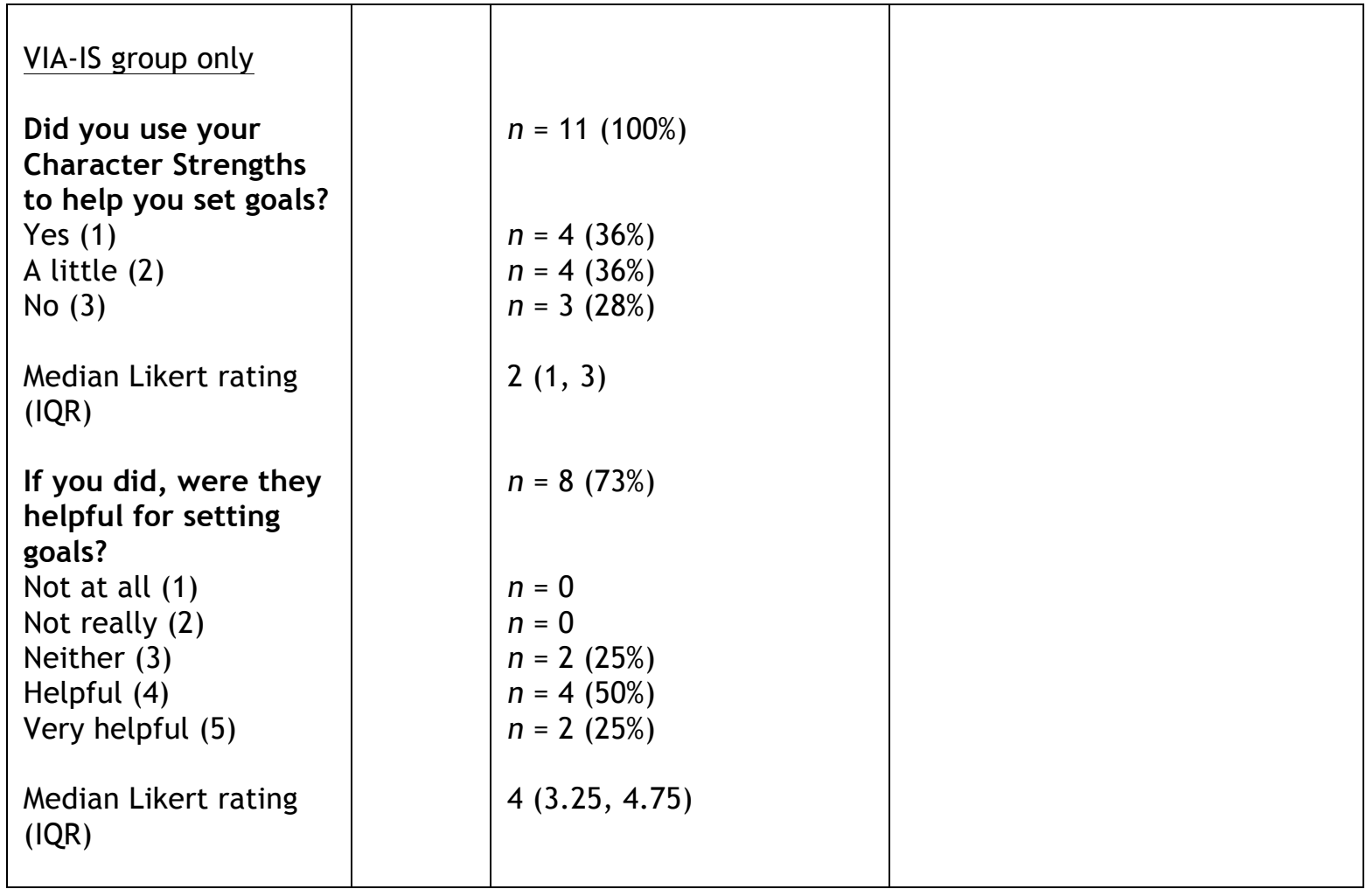


Supplemental data 2: CTCBI clinician responses about completing and using the VIA-IS

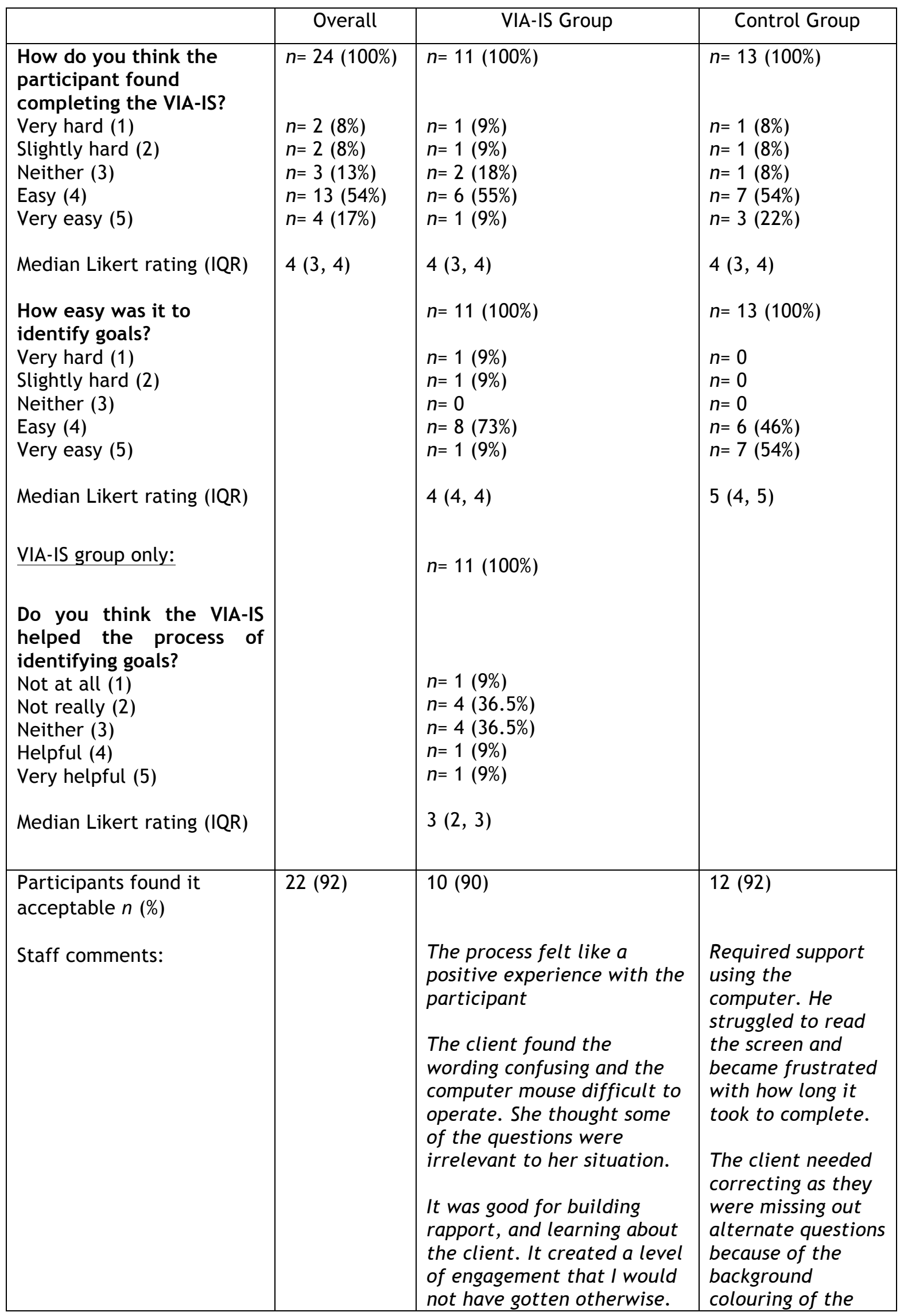




\begin{tabular}{|c|c|c|c|}
\hline & & $\begin{array}{l}\text { It helped the client to } \\
\text { articulate why the goal was } \\
\text { important to them. } \\
\text { It was a useful tool to get } \\
\text { the client to think about } \\
\text { different goals in relation to } \\
\text { different areas of her life. } \\
\text { She seemed to enjoy the } \\
\text { process. } \\
\text { The client knew what goal } \\
\text { they wanted to set from the } \\
\text { beginning }(n=2)\end{array}$ & questionnaire. \\
\hline $\begin{array}{l}\text { Participants found it not } \\
\text { acceptable } n(\%) \\
\text { Staff comments: }\end{array}$ & $2(11)$ & $\begin{array}{l}1 \text { (10) } \\
\text { Participant found it difficult } \\
\text { to fill in the VIA-IS, she } \\
\text { required support using the } \\
\text { computer, and found some } \\
\text { of the language hard to } \\
\text { understand. She was } \\
\text { thinking about herself } \\
\text { before the injury, and was } \\
\text { worried about failing. }\end{array}$ & $1(8)$ \\
\hline
\end{tabular}

